\title{
Shape Optimization of A Parabolic Trough Collector, Geometrical Considerations
}

\author{
B. El Ghazzani ${ }^{1 *}$, O. Nait Mensour ${ }^{1}$, \\ R. Ait El Cadi ${ }^{1}$, A. Ihlal ${ }^{1}$, K. Bouabid ${ }^{1}$ \\ ${ }^{1}$ Laboratory of Materials and Renewable Energy (LMER), \\ University IBN ZOHR, faculty of science BP 8106 - City \\ Dakhla, Agadir, Morocco.
}

\begin{abstract}
In the last years, solar thermal power plants based on parabolic trough concentrators (PTCs), which are the most proven type of the Concentrating Solar Power technologies (CSP), have been widely deployed in the industry sectors. Indeed, there are various applications for thermal plants in industry, such as desalination, refrigeration and air heating.

The optimization of the mirror surfaces design is basic to characterize the whole solar energy conversion system.

In this paper the basic geometrical parameters a typical PTC are presented and the optical performances of this collector is studied basing on these parameters.
\end{abstract}

Keywords- Solar energy; parabolic trough collectors; solar concentration; rim angle; optical performance.

\section{INTRODUCTION}

Through an indirect process, concentrating solar power (CSP) is an efficient means to convert solar energy into another type of energy, usually thermal.[1] CSP technologies consist of large-area of mirrors that concentrate sunlight onto a smallaperture receiver. The working fluid, called heat transfer fluid (HTF), inside the receiver can be heated to a high temperature, and then the hot fluid can be used to either directly run a thermodynamic power cycle or generate another working fluid at high temperature through a heat exchanger to run the cycle in order to generate electricity or for another use[2].

Several developing countries like Mexico, Egypt, India, and Morocco are moving to concentrating solar power for electricity[3]. A technology assessment shows that CSP plants could play a promising role in these countries and generally in Africa and Europe where the level of solar radiation is high, helping to reach ambitious climate protection goals [4][5].

In general, CSP technologies can be classified in four types: [6] parabolic trough, linear Fresnel, central receiver (tower), and dish/engine. This work will focus only on the parabolic trough collectors (PTCs) which can be considered the most mature among these concentrating solar technologies.

The common concentrating design requires the use of mirrors. [7] As mentioned earlier the parabolic profile is one of the most widespread because of its construction properties and a reasonably good manufacture feasibility [8].

The optimization of the mirror surfaces design is basic to characterize the whole solar energy conversion system [9], it is the most responsible for the radiation collection. In real plants working conditions, several misalignment errors between the solar rays and the collector axis would arise, a part of them are related with the environment where the system is built, others concern the concentrator itself [10].

\author{
R. Ait El Cadi ${ }^{2}$ \\ ${ }^{2}$ Laboratory of Thermodynamics and Energy (LTE), \\ University IBN ZOHR, faculty of science BP 8106 - City \\ Dakhla, Agadir, Morocco.
}

First of all, it is suitable to describe and explain the most important parameters of a typical parabolic trough collector (PTC) and makes recommendations to reach good performance. A short description of the PTC energy balance is also presented in this paper. In the purpose to evaluate the optical performances of a PTC, the geometrical parameters are taken into consideration in this paper.

\section{MAIN PTC PARAMETERS}

Commercial PTC designs for solar thermal power plants are generally $100 \mathrm{~m}$ to $150 \mathrm{~m}$ long and have a parabola width of about 6-m, while PTC designs for industrial heat use are remarkably smaller [11]. Parabolic trough collectors require solar tracking systems to modify their position with the changing apparent sun position in the sky from sunrise to sunset. Movement of this type of solar collector has only one degree of freedom, on-axis rotation [12].

The most important PTC parameters are the geometric concentration ratio, acceptance angle, rim angle, and peak optical efficiency [13]. The following paragraphs explain these parameters and others.

The geometric characteristics of a parabolic trough collector from a lateral plane are depicted in Fig.1 as follow:

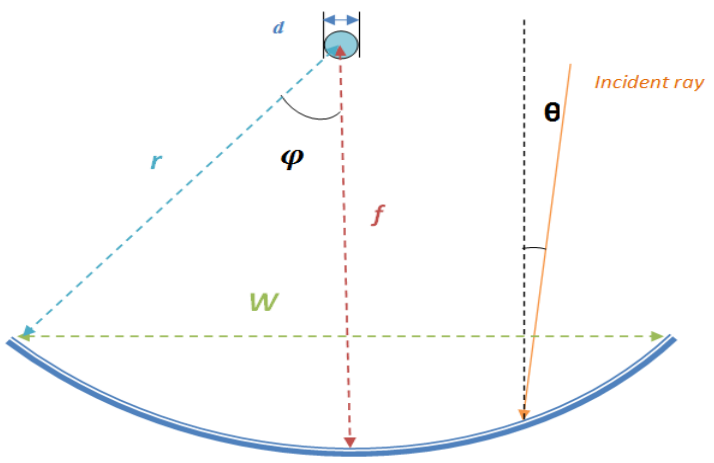

Figure 1: Principal geometrical characteristics of a PTC (Cross-sectional view)

- $\mathrm{f}$ is the parabola focal length;

- $\mathrm{d}$ is the absorber diameter;

$\circ \quad \mathrm{W}$ is the collector width;

$\circ \quad \mathrm{r}$ is the distance between the focus and the end point of the profile;

- $\varphi$ is the rim angle of the collector formed by the normal axis and the straight line from the focus to the end point of the profile;

$\circ \boldsymbol{\theta}$ is the incoming rays angle in respect to the parabola axis (the incidence angle). 
A. The rim angle

The rim angle, $\boldsymbol{\varphi}$, is directly related to the concentrator arc length and the focal length as shown in Fig.5.1, it can be calculated as a function of the parabola focal distance, $\mathrm{f}$, and aperture width, $\mathrm{W}$ and can expressed as follow:

$$
\frac{f}{w}=\frac{1+\cos \varphi}{4 \sin \varphi}
$$

\section{B. The geometric concentration ratio, $\boldsymbol{C g}$}

The geometric concentration ratio, $\boldsymbol{C g}$, is the ratio between the collector aperture area and the total absorber tube area as presented in Fig.1 and Fig.2(b). The Geometric concentration ratio, $\boldsymbol{C g}$, is given by the equation [13] [14]:

$$
C_{g}=\frac{w \cdot l}{\pi \cdot d \cdot l}=\frac{w}{\pi \cdot d}=\frac{\sin \varphi}{\pi \sin \theta}
$$

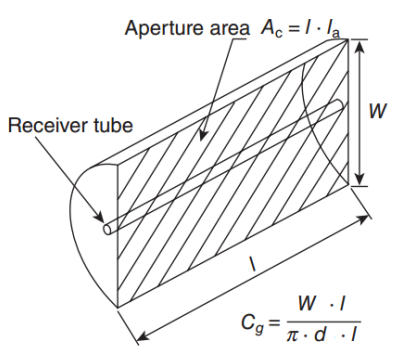

(a)

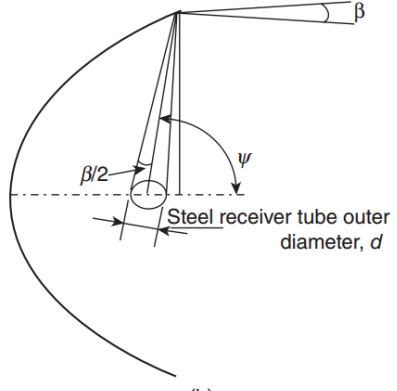

(b)
Figure 2: (a) Geometric concentration ratio, $\mathrm{Cg}$ and (b) acceptance angle, $\beta$ and aperture angle, $\psi$ of a parabolic-trough collector. [13]

\section{The acceptance angle}

The acceptance angle, $\beta$, is the maximum angle that can be formed by two rays on a plane transversal to the collector aperture in such a way that, when they are reflected by the parabolic mirrors, they intercept the absorber tube. Fig.2 (b) illustrates this angle.

Small acceptance angles are associated with high concentration ratios, which require the installation of very accurate solar tracking systems and, consequently, higher costs. The minimum acceptance angle is $\left(0.53^{\circ}\right)$, which is the average solid angle with which the solar disk as seen from the Earth. Therefore, any PTC with an acceptance angle smaller than $0.53^{\circ}$ would always lose a fraction of the direct solar radiation. [13] In fact, recommended acceptance angles for commercial PTCs are in the range of 1 to $2^{\circ}$. So most commercial PTC designs have acceptance angles within the range of $1-2^{\circ}$, with geometric concentration ratios of 20 to 30. [13]

\section{Optical losses}

The importance of optical losses in parabolic-trough collectors comes from the fact that they are about $25 \%$ of the total solar flux incident on the PTC aperture plane. Optical losses are associated with the four parameters presented below (see Fig.3).

- Reflectivity, $\rho$, of the collector reflective surface.

- Intercept factor, $\gamma$. A fraction of the direct solar radiation reflected by the mirrors does not reach the active surface of the receiver pipe due to either reflector microscopic imperfections, macroscopic errors in the parabolic-trough concentrator shape (e.g., inaccuracies during assembly) or mechanical deformation, etc. This optical parameter is typically within the $0.91-0.93$ range for high-quality PTCs [13].

- Transmissivity, $\boldsymbol{\tau}$ of the glass cover. This parameter presents the ratio of the radiation passing through the glass cover to the total incident radiation.

- Absorptivity, $\boldsymbol{\alpha}$ of the receiver selective coating. This parameter describes the amount of energy absorbed by the steel receiver pipe over the total radiation reaching its outer wall.

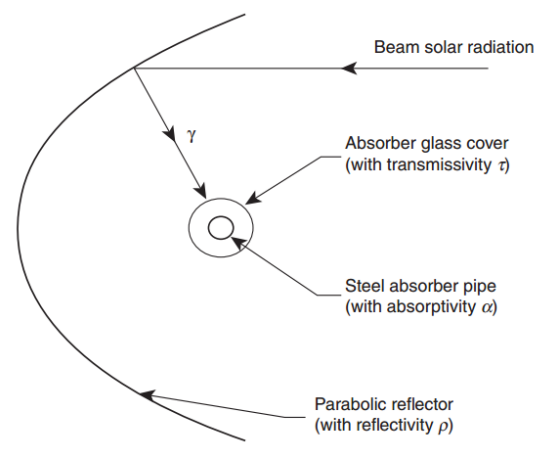

Figure 3: Optical losses in a parabolic-trough collector [13]

\section{E. The Incidence Angle Modifier (IAM)}

The incidence angle of the direct solar radiation, $\theta$, (Fig.4) affects the four optical parameters mentioned earlier and the useful aperture area of the collector. This effect is quantified by the incidence angle modifier, called IAM or $K(\theta)$.

Therefore, in addition to the losses due to the angle of incidence, there are other losses on collectors that can be correlated to the angle of incidence. These losses are due to the additional reflection and absorption of the glass envelope as the angle of incidence varies. The incidence angle modifier $(I A M)$ corrects these additional losses of reflection and absorption. This parameter represents an empirical correlation to experimental data on a parabolic trough collector. It includes all optical and geometric losses in a PTC generated by an incidence angle greater than $0^{\circ}$, without including the $\cos \theta$ effect.

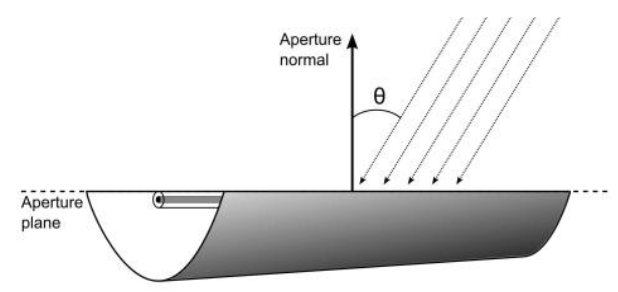

Figure 4: The angle between the solar irradiation and the normal vector to the collector aperture plane (Incidence angle). [15] 


\section{F. The peak optical efficiency of the PTC, $\boldsymbol{\eta}_{\text {opt }, \mathbf{0}}$}

The peak optical efficiency is given by the multiplication of these four parameters (reflectivity, intercept factor, glass transmissivity, and absorptivity of the steel pipe) when the incidence angle, $\theta$, of the solar rays onto the PTC aperture plane is $0^{\circ}$, and it is expressed as follow:

$$
\eta_{o p t, 0}=\rho \times \gamma \times \tau \times\left.\alpha\right|_{\theta=0^{\circ}}
$$

$\eta_{\text {opt }, 0}$ is usually in the range of $0.74-0.79$ for goodquality, clean parabolic trough collectors [13].

The multiplication of the peak optical efficiency, $\eta_{\text {opt }, 0}$, by the incidence angle modifier, $K(\theta)$ gives us the part of the direct solar radiation reaching the PTC aperture plane with the incidence angle $\boldsymbol{\theta}$ that is absorbed by the receiver pipe.

$$
\eta_{\text {opt }, \theta \neq 0^{\circ}}=\eta_{\text {opt }, 0} K(\theta)
$$

\section{G. Energy balance in a PTC}

There are three sources of energy loss in a typical PTC, and are presented as follow:

- optical losses due to mirror reflectivity, intercept factor, glass transmissivity and absorptance of the receiver tube when the solar radiation incidence angle is equal to $0^{\circ}, \eta_{o p t, 0}$.

- additional optical and geometrical losses due to an incidence angle greater than $0^{\circ}, K(\theta)$; these additional losses do not exist when the incident angle is equal to $0^{\circ}$ because $K(\theta=0)=1$

- Thermal losses from the receiver pipe to the ambient, $Q_{\text {collector-ambient }}$.

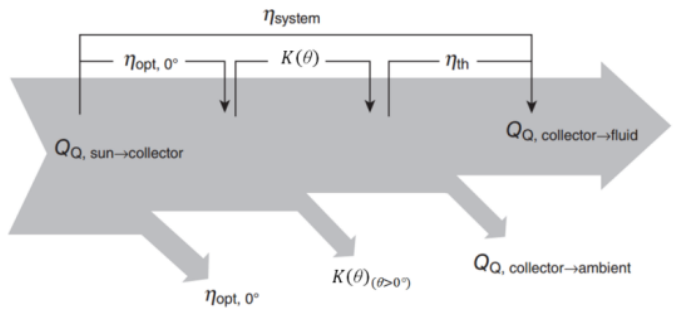

Figure 5: Energy balance in a parabolic-trough collector [13]

The net thermal output can be theoretically calculated from the energy balance shown in Fig.5, and direct solar irradiance, $\boldsymbol{D N I}$, ambient air temperature, incidence angle, $\boldsymbol{\theta}$, and PTC optical, thermal and geometrical parameters, in addition to the soiling factor, $\boldsymbol{F e}$, which is calculated as the ratio between average PTC mirror reflectivity during real operation and the nominal reflectivity when the PTC is completely clean. This net thermal output can be given by the following equation:

$$
\begin{aligned}
& Q_{\text {collector_fluid }} \\
& =A_{c} \cdot D N I \cdot \cos \theta \eta_{\text {opt }, 0} \cdot K(\theta) . F_{e} \\
& -Q_{\text {collector_ambient }}
\end{aligned}
$$

\section{Row shadowing}

Shadowing between rows particularly occurs at extreme solar positions when the shadow cast by a collector closer to the sun obscures a portion of an adjacent collector. Fig.6 presents the geometry associated with row shadowing.

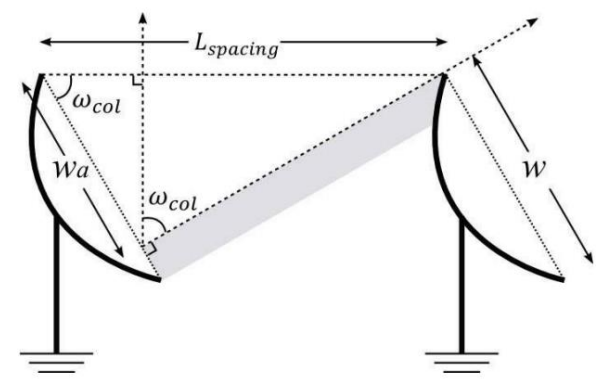

Figure 6: Two adjacent collector rows shadowing each other. [15]

The shadowing efficiency is equal to the ratio of the nonshadowed aperture to the total aperture width, w, as shown in Equation 6.

$$
\eta_{\text {shadow }}=\frac{W_{a}}{W}=\left|\cos \omega_{\text {col }}\right| \cdot \frac{L_{\text {Spacing }}}{W}
$$

\section{End losses}

At the ends of the receiver, the end losses occur. For nonzero incidence angle, some parts at the extremities of the absorber tube are not illuminated by the solar radiation reflected by the mirror. Fig.7 depicts the end losses by an absorber tube.

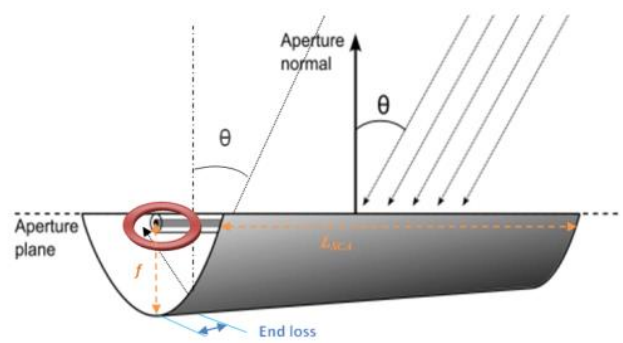

Figure 7: End losses by the absorber tube of a PTC. (Modified from [15] )

The end losses appear on the absorber tube in the case of non-zero incidence angle. The end losses parameter is a function of the focal length of the PTC, its proper length, and the incidence angle. It is given by the following equation [16]:

$$
E=1-f \cdot \frac{\tan \theta}{L_{S C A}}
$$

\section{SHAPE OPTIMIZATION OF A PTC, GEOMETRICAL CONIDERATIONS}

From an optical point of view, light is considered as rays carrying power through a transmission medium and interacting with reflective and diffractive surfaces.

The definition of the concentration ratio of the parabolic trough collector takes into account a cylindrical absorber that is fully hit by the rays reflected from the mirror. It is clear to assure that the CR becomes lower when the incidence angle increases.

The trends for a rim angle equal to $90^{\circ}$ and the one equal to $71^{\circ}$ which is the value used in the commercial Polytrough 1800 , also the one equal to $50^{\circ}$ of the Polytrough 1200 , are reported in Fig.8. In fact, the parameter $\boldsymbol{\theta}$ is very relevant and 
values near $1^{\circ}$ are sufficient to cut down the concentration level for the three rim angle values. The variation of the rim angle value influences also the concentration ratio of the PTC for different incidence angle values.

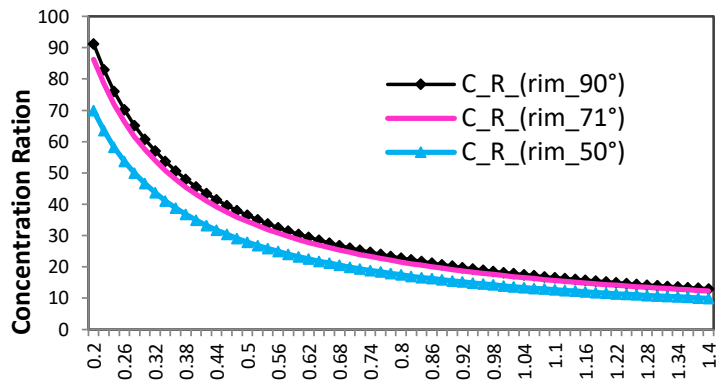

$\theta 0^{\circ}$

Figure 8: The variation of the geometrical concentration ratio as function of the incidence angle

According to Equation 1 and Equation 2, for every value of $\boldsymbol{\theta}$, the maximum concentration ratio can be reached when the rim angle is $90^{\circ}$ and $\mathrm{f} / \mathrm{c}$ is equal to 0.25 , without taking into considerations the concentrator absolute dimensions.

Related curves are shown and the particular cases for $\boldsymbol{\theta}$ equal to $0.25,0.5^{\circ}$, and $1^{\circ}$. Figures Fig.9 and Fig. 10 illustrate these curves. The Fig.11 presents the concentration ratio variation as function of the both rim angle and the incidence angle.

This concentration ratio is usually about 25 and High concentration ratios are associated with higher working temperatures[13]. Although theoretically, the maximum is on the order of 72 for the case a PTC with $\boldsymbol{\varphi}$ equal to $90^{\circ}$ as presented in figures bellow. This maximum decreases when the $\boldsymbol{\theta}$ value increases.

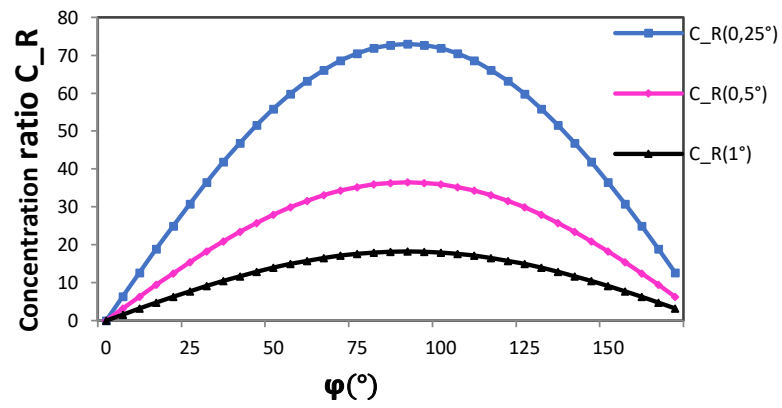

Figure 9: The variation of the geometric concentration ratio as function of rim angle $\varphi$, for three values of $\boldsymbol{\theta}$

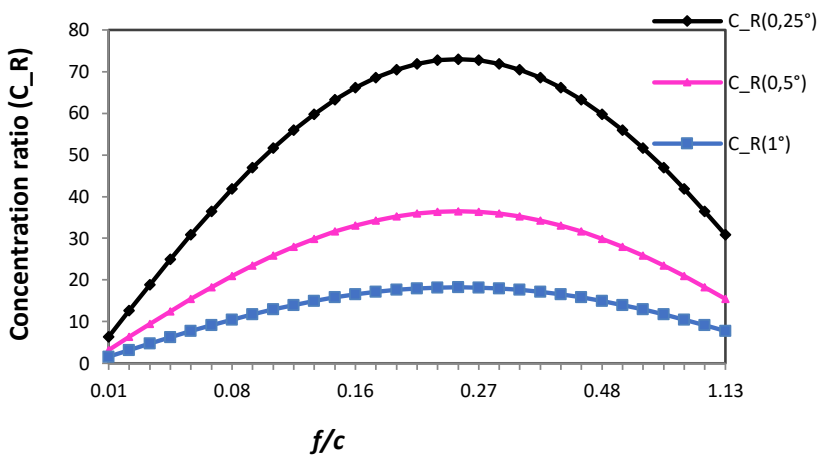

Figure 10: The variation of the geometric concentration ratio as function of (f/c), for three values of $\boldsymbol{\theta}$

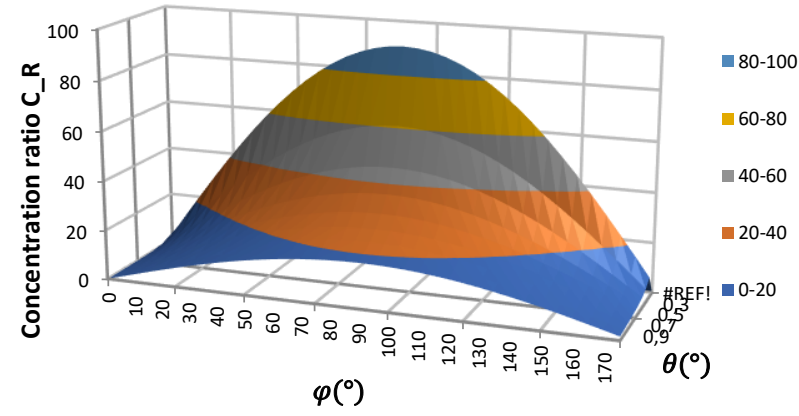

Figure 11: The variation of the geometric concentration ratio as function of rim angle $\varphi$ and $\boldsymbol{\theta}$

This study makes possible to define the shape of a parabolic trough collector that optimizes the optical efficiency. The calculations depict that the rim angle of $90^{\circ}$ is the best in order to have a PTC with the optimal concentration ratio.

\section{CONCLUSION}

In this paper, the main parameters of a typical parabolic trough collector are discussed, then, for the aim to evaluate the optical performances of a PTC, a study about its shape optimization is performed. The definition of the optimized shape of a parabolic through collectors is possible through this study. The calculations show that the rim angle of $90^{\circ}$ is the best in order to have a PTC with the optimal concentration ratio.

After that a modelling of a parabolic trough collector using the Ray Tracing approach of Monte Carlo method under SolTrace software is mandatory in order to validate this conclusion.

\section{ACKNOWLEDGMENT}

This work is supported by IRESEN (Institut de Recherche en Energie Solaire et Energies Nouvelles, MOROCCO) in the framework of the project InnoTherm.

\section{REFERENCES}

A. Fernandez-Garcia, E. Zarza, L. Valenzuela, and M. Pérez, "Parabolic-trough solar collectors and their applications," Renew. Sustain. Energy Rev., vol. 14, pp. 1695-1721, 2010, doi 10.1016/j.rser.2010.03.012

[2] R. A. El Cadi et al., "Power Generation and Heating Performances of An Organic Rankine Cycle Driven by Parabolic Trough Collectors," vol. 8, no. 10, pp. 115-120, 2019. 
[3] O. N. Mensour, S. Bouaddi, B. Abnay, B. Hlimi, and A. Ihlal, "Mapping and Estimation of Monthly Global Solar Irradiation in Different Zones in Souss-Massa Area , Morocco , Using Artificial Neural Networks," Int. J. Photoenergy, vol. 2017, 2017.

[4] P. Viebahn, Y. Lechon, and F. Trieb, "The potential role of concentrated solar power ( CSP ) in Africa and Europe - A dynamic assessment of technology development, cost development and life cycle inventories until 2050," Energy Policy, vol. 39, no. 8 pp. 4420-4430, 2011, doi: 10.1016/j.enpol.2010.09.026

[5] B. El Ghazzani, D. Martinez Plaza, R. Ait El Cadi, B. Abnay, A Ihlal, and K. Bouabid, "Thermal plant based on parabolic trough collectors for industrial process heat generation in Morocco," Renew. Energy, vol. 113, pp. 1261-1275, 2017, doi: 10.1016/j.renene.2017.06.063.

[6] D. Mills, "Advances in solar thermal electricity technology," Sol. Energy, vol. 76, pp. 19-31, 2004, doi: 10.1016/S0038092X(03)00102-6.

[7] H. Price et al., "Advances in Parabolic Trough Solar Power Technology," J. Sol. Energy Eng., vol. 124, no. 2, p. 109, 2002, doi: $10.1115 / 1.1467922$

[8] A. Fernandez-Garcia, E. Rojas, P. Manuel, R. Silva, Q. HernandezEscobido, and F. Manzano-agugliaro, "A parabolic-trough collector for cleaner industrial process heat nzazu Fern a d," J. Clean. Prod. J., 2014, doi: 10.1016/j.jclepro.2014.11.018.

[9] J. Xiao, X. Wei, Z. Lu, W. Yu, and H. Wu, "A review of available methods for surface shape measurement of solar concentrator in solar thermal power applications," Renew. Sustain. Energy Rev, vol. 16, no. 5, pp. 2539-2544, 2012, doi: 10.1016/j.rser.2012.01.063.

[10] K. Lovegrove and J. Pye, "Fundamental principles of concentrating solar power (CSP) systems," 2012, pp. 16-67.

[11] M. Borunda, O. A. Jaramillo, R. Dorantes, and A. Reyes, "Organic Rankine Cycle coupling with a Parabolic Trough Solar Power Plant for cogeneration and industrial processes," Renew. Energy, 2016 doi: 10.1016/j.renene.2015.08.041

[12] A. Lokurlu and F. Richarts, "High efficient utilisation of solar energy with newly developed parabolic trough collectors ( SOLITEM PTC ) for chilling and steam production in a hotel at the Mediterranean coast of Turkey Ahmet Lokurlu * and Fritz Richarts Dirk Krüger," int. J. Energy Tech Policy, vol. 3, pp. 137-146, 2005.

[13] E. Zarza, "Parabolic trough concentrating solar power (CSP) systems," Woodhead Publ. Ltd., 2012, doi: 10.1533/9780857096173.2.197.

[14] G. Pierucci, D. Fontani, P. Sansoni, and M. De Lucia, "Shape optimization for parabolic troughs working in non-ideal conditions," Energy Procedia, vol. 57, pp. 2231-2240, 2014, doi: 10.1016/j.egypro.2014.10.230

[15] M. J. Wagner and P. Gilman, "Technical Manual for the SAM Physical Trough Model Technical Manual for the SAM Physical Trough Model," no. June, 2011.

[16] F. Lippke, "Simulation of the Part Load Behavior of a 30MWe SEGS Plant.," Albuquerque, 1995. 